\title{
Effects of adiponectin on osteoclastogenesis from mouse bone marrow-derived monocytes
}

\author{
XIA WU ${ }^{1}$, LEITAO HUANG ${ }^{2}$ and JICHUN LIU ${ }^{1}$ \\ Departments of ${ }^{1}$ Thoracic and Cardiovascular Surgery and ${ }^{2}$ Orthopedics, \\ The First Affiliated Hospital of Nanchang University, Nanchang, Jiangxi 330006, P.R. China
}

Received March 13, 2018; Accepted October 5, 2018

DOI: $10.3892 /$ etm.2018.7069

\begin{abstract}
The aim of the present study was to investigate the effects of adiponectin on bone marrow-derived monocytes (BMMs) in the process of osteoclastogenesis. Primary BMMs derived from the mouse bone marrow were cultured, which were then treated with different concentrations of adiponectin and macrophage colony stimulating factor (M-CSF). Cell viability was determined by measuring the absorbance after $24 \mathrm{~h}$ with Cell Counting Kit-8 reagent. BMM cells treated with adiponectin and receptor activator of nuclear factor- $\kappa \mathrm{B}$ ligand (RANKL) were induced and differentiated to mature osteoclasts for 1 week, and then stained with tartrate-resistant acid phosphatase (TRAP). The number of osteoclasts was evaluated under light microscopy. The expression of adiponectin in BMMs at the gene and protein levels was further assessed with reverse transcription-quantitative polymerase chain reaction and western blotting, respectively. The cellular proliferation experiment demonstrated that the optical density value decreased gradually with an increase of adiponectin concentration, with statistically significant differences detected among groups. In addition, the number of osteoclasts in the adiponectin-treated group was significantly reduced compared with that in the control group. Adiponectin expression was confirmed in BMMs at both the protein and mRNA levels. In conclusion, the present data demonstrated that adiponectin has a significant inhibitory effect on the osteoclast differentiation and proliferation of BMMs, suggesting a novel strategy for preventing osteoporosis.
\end{abstract}

Correspondence to: Professor Jichun Liu, Department of Thoracic and Cardiovascular Surgery, The First Affiliated Hospital of Nanchang University, 17 Yong Wai Zheng Street, Nanchang, Jiangxi 330006, P.R. China

E-mail: 504716243@qq.com

Abbreviations: BMMs, bone marrow-derived monocytes; M-CSF, macrophage colony stimulating factor; OP, osteoporosis; TNF, tumor necrosis factor; TRAP, tartrate resistant acid phosphatase; CCK-8, cell counting kit-8; RANKL, receptor activator of nuclear factor- $\kappa \mathrm{B}$ ligand; FBS, fetal bovine serum; ANOVA, analysis of variance

Key words: adiponectin, osteoclastogenesis, bone marrow-derived monocytes, nuclear factor- $\mathrm{\kappa} \mathrm{B}$ signaling, osteoporosis

\section{Introduction}

As mesenchymal stem cells have the ability for differentiation into osteoclasts, they have become important multifunctional seeds for bone tissue engineering research (1). When the ability of this directional differentiation is strengthened or suppressed, it disrupts the balance of bone-related metabolism in the body, which is a main cause of osteoporosis (OP) development (2). However, the search for effective strategies for preventing OP remains an active and challenging area of research.

OP is a metabolic bone disease characterized by a reduction of bone mass, mainly due to the augmentation of bone absorption (3). The occurrence of OP is directly associated with the activity of osteoblasts and osteoclasts, particularly the process of osteoclastogenesis. OP is associated with an increased risk of fracture and mortality, representing a classic aging-associated disease (4-6); the lifetime risk of an osteoporotic fracture in men over the age of 50 is $30 \%$ (7). Vitamin D3 is the traditional treatment for OP, but these effects are insufficient to completely explain the anti-OP mechanism (8). Thus, novel anti-OP drugs are required, warranting further research to identify novel drug targets. Recent studies (9) have demonstrated a close correlation between adiponectin and bone metabolism, suggesting a possible candidate for the OP pathogenic mechanism and treatment target.

Adiponectin is mainly secreted by adipocytes and serves an important role in preventing obesity, diabetes and atherosclerosis (10-12). Adiponectin was demonstrated to inhibit receptor activator of nuclear factor $(\mathrm{NF})-\kappa \mathrm{B}$ ligand (RANKL)-induced osteoclast differentiation, and showed a significant negative correlation with bone mineral density (BMD) $(13,14)$. RANK can be combined with its ligand RANKL or other members of the tumor necrosis factor (TNF) ligand family, and osteoclast precursor cells can continuously generate RANK. Once the content of RANK in the body is reduced, osteoclast progenitor cell proliferation is rapidly promoted through the negative feedback system, and osteoclastogenesis is simultaneously stimulated to markedly enhance bone absorption ability, contributing to OP $(15,16)$. However, previous studies have demonstrated that adiponectin knockout in mice causes a significant increase in the number of mature osteoclasts compared to that in wild type mice, suggesting that adiponectin blocks the activity of osteoblasts to directly or indirectly stimulate osteoclast differentiation 
and osteoclastogenesis, resulting in obvious bone absorption and bone loss leading to OP $(17,18)$. However, a role of adiponectin in promoting osteoclasts has only been reported by a few studies $(13,19)$ and thus it is possible that this effect only occurs under certain conditions, and not universally.

Monocytes/macrophages and neutrophils can produce a large amount of adiponectin in response to inflammation (i.e., acute host defense against microorganisms, arthritis, and endotoxin shock), and adiponectin can regulate the bone metabolism effects in many types of cells, including osteoblasts, chondrocytes and osteoclasts (20-24). However, to the best of our knowledge, the effects of adiponectin on bone marrow-derived monocytes (BMMs) have not been demonstrated to date. Therefore, the aim of the present study was to investigate the effects of adiponectin treatment in mouse BMMs and determine its overall influence on osteoclastogenesis.

\section{Materials and methods}

Ethics and BMM culture. All animal experiments were conducted following the approval of the Institutional Review Board (Medical Ethics Committee) of the First Affiliated Hospital of Nanchang University (Nanchang, China). Primary bone marrow samples were obtained from the long bones (i.e., the femur and tibia) of 4-6-week-old C57BL/6 male mice, as previously described $(25,26)$. A total of 15 C57BL/6 male mice were purchased from the Department of Animal Science (Nanchang University, Nanchang, China). Animals were housed at $18-22^{\circ} \mathrm{C}$ with $50-60 \%$ humidity using 12 -h light/dark cycles. Animals were fed in regular intervals: 3-7 g/day/animal; 3-4 times per week; water ad libitum. In brief, bone marrow cells were cultured in a T75 flask in complete $\alpha$-minimal essential medium ( $\alpha$-MEM) supplemented with $10 \%$ fetal bovine serum (FBS) (both from Gibco; Thermo Fisher Scientific, Inc., Waltham, MA, USA), $1 \%$ penicillin/streptomycin, and $50 \mathrm{ng} / \mathrm{ml}$ macrophage colony stimulating factor (M-CSF; R\&D Systems, Inc., Minneapolis, MN, USA) at $37^{\circ} \mathrm{C}$ in a humidified atmosphere $\left(5 \% \mathrm{CO}_{2}, 95 \%\right.$ air) for $24 \mathrm{~h}$. Non-adherent cells were subsequently collected and reseeded in another T75 flask to continue incubation. Following culture for 3-4 days, medium was replaced and the culture was washed gently with phosphate-buffered saline (PBS) three times to remove impurities and non-adherent cells; adherent cells were used as the BMMs. Cell culture was continued for $\sim 3$ days until the cells reached $90 \%$ confluence. BMMs were collected by trypsin digestion, and then the cells were continuously cultured in fresh plates or prepared for subsequent experiments.

Cell viability assay. To clarify the effects of adiponectin on the growth and proliferation of BMMs, the Cell Counting Kit-8 (CCK-8; Dojindo Molecular Technologies, Inc., Kumamoto, Japan) assay was conducted according to the manufacturer's instructions. In brief, the BMMs were treated with various concentrations of adiponectin $(0,0.2,1$ and $5 \mu \mathrm{g} / \mathrm{ml}$; Sinopharm Chemical Reagent Co., Ltd., Shanghai, China) in 96-well plates at a density of $5 \times 10^{3}$ cells/well and cultured with $\alpha$-MEM supplemented with $10 \% \mathrm{FBS}$ and $50 \mathrm{ng} / \mathrm{ml} \mathrm{M-CSF}$ at $37^{\circ} \mathrm{C}$ for $24 \mathrm{~h}$, and $10 \mu \mathrm{lCCK}-8$ solution was added to each well and incubated for another $2 \mathrm{~h}$ at $37^{\circ} \mathrm{C}$. The absorbance was then detected at a wavelength of $450 \mathrm{~nm}$ on an ELX800
HT spectrophotometer (Bio-Tek Instruments Inc., Winooski, VT, USA). Cell viability was calculated relative to that of the control group. The experiment was repeated three times independently. The viability and growth of BMMs were plotted and statistically compared using GraphPad Prism 5.0 software.

Osteoclastogenesis assay. The BMMs were plated in a 96-well plate at $5 \times 10^{3}$ cells/well. The cells were cultured in complete $\alpha$-MEM supplemented with $10 \%$ FBS, $1 \%$ penicillin/streptomycin, and $50 \mathrm{ng} / \mathrm{ml} \mathrm{M-CSF}$, along with $50 \mathrm{ng} / \mathrm{ml} \mathrm{RANKL}$ (PeproTech, Inc., Rocky Hill, NJ, USA) and different concentrations of adiponectin $(0,0.2,1$ and $5 \mu \mathrm{g} / \mathrm{ml})$. The cell culture medium was changed every 2 days until the mature osteoclasts formed ( $\sim 1$ week). The cells were then washed with PBS three times. The cells were fixed in $4 \%$ buffered paraformaldehyde for $30 \mathrm{~min}$ at $37^{\circ} \mathrm{C}$ and stained for tartrate-resistant acid phosphatase (TRAP) at $37^{\circ} \mathrm{C}$ for $1 \mathrm{~h}$. The number and area of multinucleated (two or more nuclei) TRAP-positive cells were counted in all wells under a light microscope (magnification, x100).

Reverse transcription-quantitative polymerase chain reaction (RT-qPCR) assay. RT-qPCR was used to determine the mRNA expression level of adiponectin in the BMMs. Following three generations of BMM culture, cells were seeded in 6-well plates in $\alpha$-MEM supplemented with $10 \%$ FBS, $1 \%$ penicillin/streptomycin and $50 \mathrm{ng} / \mathrm{ml} \mathrm{M-CSF}$, with or without $1 \mu \mathrm{g} / \mathrm{ml}$ adiponectin, and incubated at $37^{\circ} \mathrm{C}$ for $24 \mathrm{~h}$. Total RNA was then extracted from each well using TRIzol reagent (Life Technologies; Thermo Fisher Scientific, Inc.) following the manufacturer's suggestion. Total RNA (1 mg) was used to prepare cDNA using reverse transcriptase (Takara Bio, Inc., Otsu, Japan). Samples contained total RNA $(2 \mu \mathrm{l})$, anchored oligo (DT) $)_{18}$ primer $(0.5 \mu \mathrm{g} / \mu \mathrm{l} ; 1 \mu \mathrm{l})$, random primer $(0.1 \mu \mathrm{g} / \mu \mathrm{l} ; 1 \mu \mathrm{l}), 2 \mathrm{X}$ ES reaction mix $(10 \mu \mathrm{l})$, EasyScript RT/RI Enzyme mix (1 $\mu \mathrm{l})$, gDNA remover $(1 \mu \mathrm{l})$ and water to $20 \mu \mathrm{l}$. The mixture was incubated for $10 \mathrm{~min}$ at $25^{\circ} \mathrm{C}$ and reverse transcribed at $42^{\circ} \mathrm{C}$ for $15 \mathrm{~min}$. cDNA samples ( $2 \mu \mathrm{l}$ per $20 \mu \mathrm{l}$ reaction) were then used as templates for qPCR to detect the expression of the gene of interest and reference gene (adiponectin and GAPDH, respectively). qPCR was performed using SYBR Premix Ex Taq II (Tli RNaseH Plus; DRR820A; Takara Bio, Inc.) with an ABI StepOnePlus system (Applied Biosystems; Thermo Fisher Scientific, Inc.) under the following cycling conditions: Initial denaturation at $95^{\circ} \mathrm{C}$ for $5 \mathrm{~min}, 40$ cycles of denaturation at $95^{\circ} \mathrm{C}$ for $10 \mathrm{sec}$, and amplification at $60^{\circ} \mathrm{C}$ for $30 \mathrm{sec}$, with a final extension for $30 \mathrm{sec}$ at $72^{\circ} \mathrm{C}$. All expression levels were calculated using the $2^{-\Delta \Delta \mathrm{Cq}}$ method as described previously (27). GAPDH was used as a control for normalizing gene expression levels. Each sample was repeated three times. The following primers were used: GAPDH, forward, 5'-TGACCTCAACTA CATGGTCTACA-3' and reverse, 5'-CTTCCCATTCTCGGCC TTG-3'; and adiponectin, forward, 5'CATGCCCATTCGCT TTACCA-3' and reverse, 5'-GGAGGCCTGGTCCACATTAT-3'.

Western blotting. Generation-three BMMs were seeded in a 10 -cm-diameter petri dish at a density of $5 \times 10^{5}$ cells/petri dish and cultured in $\alpha$-MEM supplemented with $10 \% \mathrm{FBS}, 1 \%$ penicillin/streptomycin, and with $0,10,30$, or $50 \mathrm{ng} / \mathrm{ml} \mathrm{M-CSF}$ at $37^{\circ} \mathrm{C}$. When the cells were fully confluent, they were washed with PBS three times, and $5 \mu$ l protease inhibitor (Sigma-Aldrich; 


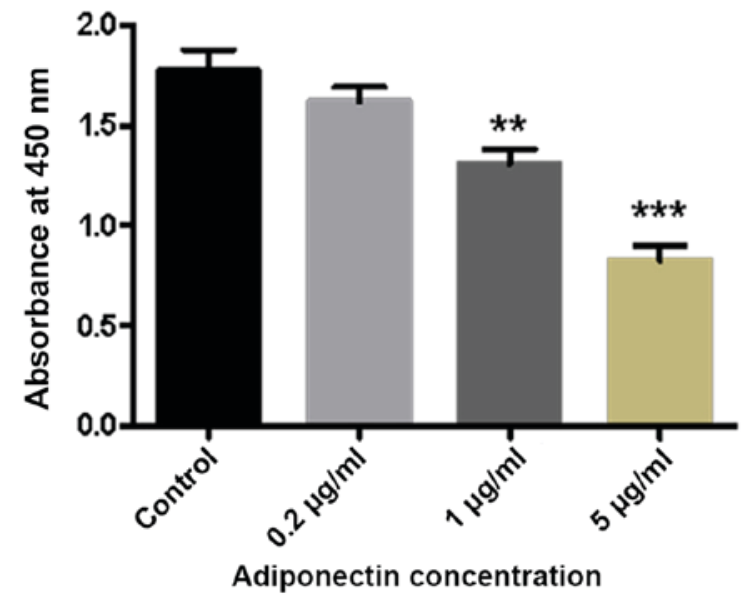

Figure 1. The effect of adiponectin on BMM viability. Adiponectin inhibits BMMs growth in a concentration-dependent manner. BMMs were incubated in the presence of macrophage colony stimulating factor and with $0.2,1$ and $5 \mu \mathrm{g} / \mathrm{ml}$ adiponectin. ${ }^{* *} \mathrm{P}<0.01,{ }^{* * *} \mathrm{P}<0.001$ vs. control. $\mathrm{BMM}$, bone marrow-derived monocytes.

Merck KGaA, Darmstadt, Germany) and $495 \mu \mathrm{l}$ radioimmunoprecipitation assay buffer (Applygen Technologies, Inc., Beijing, China) were added to each petri dish. The cells were lysed and mixed on an ice slab for $8 \mathrm{~min}$, and then transferred to EP tubes. Lysates were centrifuged at $12,000 \mathrm{x}$ g at $4^{\circ} \mathrm{C}$ for $10 \mathrm{~min}$, and the supernatants that contained the proteins were collected. Protein concentrations were measured using a bicinchoninic acid assay. A total of $25 \mu \mathrm{g}$ of each protein lysate was resolved using 10\% SDS-PAGE, and electrophoretically transferred to polyvinylidene difluoride membranes (EMD Millipore, Billerica, MA, USA). The membranes were then blocked with 5\% skimmed milk in TBS-Tween $(0.05 \mathrm{M}$ Tris, $0.15 \mathrm{M} \mathrm{NaCl} \mathrm{pH} 7.5$ and $0.2 \%$ Tween-20) for $1 \mathrm{~h}$ at room temperature, sequentially blotted with the primary antibodies anti-adiponectin 19F1 (1:1,000; cat. no. D8730) and anti- $\beta$-actin $\left(1: 2,000\right.$; cat. no. D2764) for overnight at $4^{\circ} \mathrm{C}$ and secondary antibody (horseradish peroxidase-conjugated goat anti-rabbit IgG; 1:1,000; cat. no. P1402) (all from Abcam, Cambridge, UK) for $2 \mathrm{~h}$ at room temperature and visualized using enhanced chemiluminescence (Sigma-Aldrich; Merck KGaA). The intensity of each band was analyzed using Image Lab 4.0.1 (Bio-Rad Laboratories, Inc., Hercules, CA, USA).

Statistical analysis. All statistical analyses were performed using SPSS 23.0 software (IBM Corporation, Armonk, NY, USA). The data are expressed as the means \pm standard deviation. One-way analysis of variance (ANOVA) was performed for comparisons among multiple groups, and Tukey's test was used for the post hoc test that followed ANOVA. P $<0.05$ was considered to indicate a statistically significant difference.

\section{Results}

Effects of adiponectin on the growth and proliferation of $B M M s$. The results of the CCK- 8 assay demonstrated a marked decrease in the absorbance of BMMs with increasing adiponectin concentration. Furthermore, compared with the control group, there were significant differences in cell proliferation detected in the 1 and $5 \mu \mathrm{g} / \mathrm{ml}$ adiponectin groups $(\mathrm{P}<0.01$ and $\mathrm{P}<0.001$, respectively; Fig. 1).

Effect of adiponectin on osteoclastogenesis. As presented in Fig. 2A, a large number of osteoclasts was observed in the
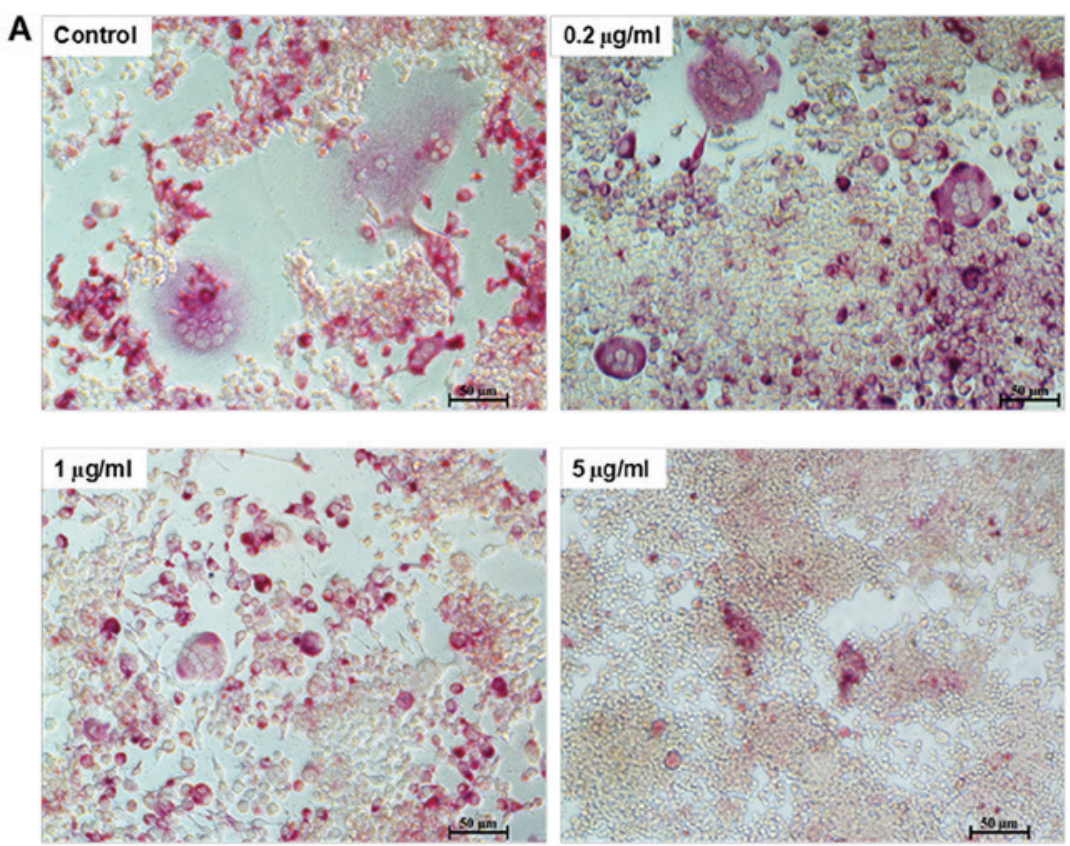
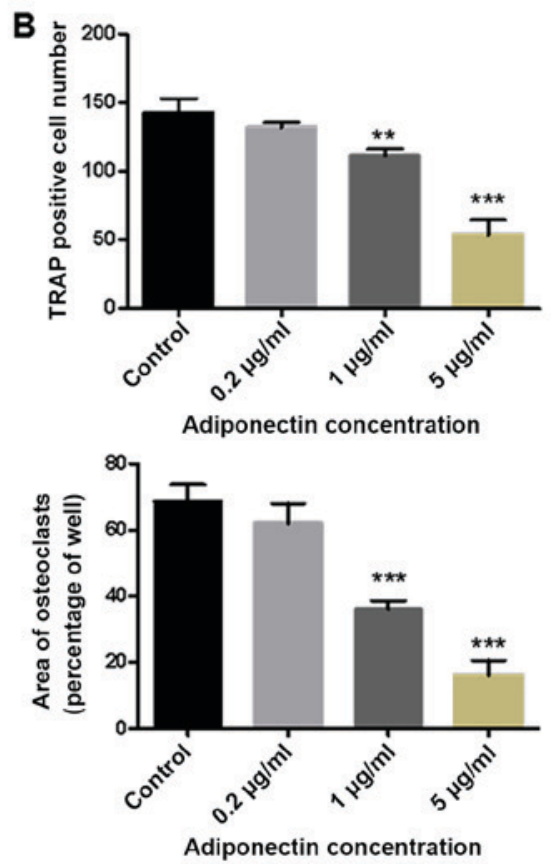

Figure 2. (A) Morphological demonstration of adiponectin inhibition of RANKL-induced osteoclast formation from BMMs. The cells were cultured for 7 days in the presence of macrophage colony stimulating factor and RANKL, and with or without adiponectin. Cells were fixed and subjected to TRAP staining (magnification, x100). (B) The number and area of TRAP-positive cells was counted. The inhibitory of adiponectin on osteoclast formation was in a concentration-dependent manner. ${ }^{* *} \mathrm{P}<0.01,{ }^{* * *} \mathrm{P}<0.001$ vs. control. RANKL, receptor activator of nuclear factor- $\kappa \mathrm{B}$ ligand; BMM, bone marrow-derived monocytes; TRAP, tartrate-resistant acid phosphatase. 


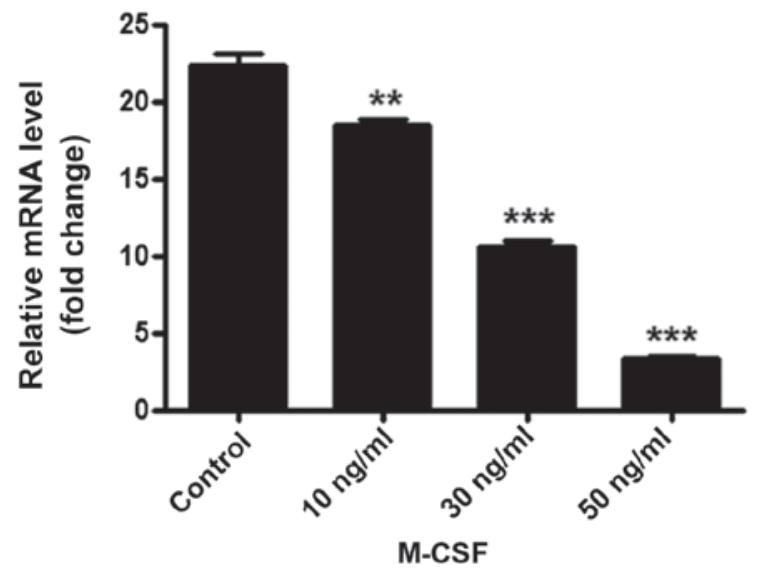

Figure 3. BMMs were stimulated with $0,10,30$ or $50 \mathrm{ng} / \mathrm{ml} \mathrm{M-CSF}$ for $24 \mathrm{~h}$ total RNA was extracted and adiponectin mRNA expression was measured using reverse transcription-quantitative polymerase chain reaction. The BMMs in the $50 \mathrm{ng} / \mathrm{ml} \mathrm{M}-\mathrm{CSF}$ group had lower expression levels of adiponectin in comparison with groups without M-CSF. All experiments were performed at least three times. ${ }^{* *} \mathrm{P}<0.01,{ }^{* * *} \mathrm{P}<0.001$ vs. control. BMM, bone marrow-derived monocytes; M-CSF, macrophage colony stimulating factor.

control group $(0 \mu \mathrm{g} / \mathrm{ml}$ adiponectin). However, treatment with $5 \mu \mathrm{g} / \mathrm{ml}$ adiponectin strongly inhibited the RANKL-induced formation of osteoclast-like multinucleated cells from the BMM cells. Both the number and area of multinucleated (two or more nuclei) TRAP-positive cells were significantly higher in the control group than in the 1 and $5 \mu \mathrm{g} / \mathrm{ml}$ adiponectin groups $(\mathrm{P}<0.01$ and $\mathrm{P}<0.001$, respectively; Fig. $2 \mathrm{~B})$.

Expression of adiponectin $m R N A$ and protein in BMMs. The qPCR results demonstrated that adiponectin mRNA is expressed in BMMs. Furthermore, with an increasing concentration of $\mathrm{M}-\mathrm{CSF}$, the adiponectin mRNA content gradually and significantly decreased $(\mathrm{P}<0.01$; Fig. 3 ). Similarly, the western blotting results demonstrated that an increasing concentration of M-CSF gradually decreased the protein expression of adiponectin in BMMs, with a particularly large decrease detected in the group treated with $50 \mathrm{ng} / \mathrm{ml}$ M-CSF. Gray value analysis of each band indicated a statistically significant difference between the groups $(\mathrm{P}<0.001$; Fig. 4).

\section{Discussion}

The present study confirms a direct effect of adiponectin on BMMs, indicating an important regulatory role in bone metabolism. First, adiponectin inhibited the growth and proliferation of BMMs in a concentration-dependent manner, which is consistent with previous findings (28). Further, adiponectin strongly inhibited RANKL-induced osteoclasts formation. Thus, the present study suggests that adiponectin serves an important role as a potent negative regulator of osteoclastogenesis in BMMs, confirming speculations of the relevant literature.

Osteoclast differentiation and formation is a complex process that is mediated by many factors, including important cytokines and signaling pathways such as M-CSF and RANKL, two key cytokines that contribute to inducing the maturation of osteoclasts (29-31). RANKL expressed on the surface of osteoblasts/interstitial cells combines with the RANK on the surface of the osteoclast precursor cells, which greatly induces differentiation into mature osteoclasts and further promotes cell proliferation (32). RANKL-RANK signaling thus serves a pivotal role in osteoclastogenesis and osteoclast function (33). Yamaguchi et al (34) previously proposed that adiponectin acts as a potent regulator of bone resorption and osteoclastogenesis. The mechanism likely comprises the suppression of the TNF- $\alpha /$ RANKL-induced differentiation of osteoclasts by interfering with TNF receptor-associated factor 6 production and calcium signaling. As $\mathrm{NF}-\kappa \mathrm{B}$ regulated by RANKL has an important role in the formation and function of osteoclasts (35), this suggests that adiponectin may be closely associated with $\mathrm{NF}-\kappa \mathrm{B}$ signaling pathways. Further, adiponectin may inhibit the expression of a key protein in the process of the induction of BMMs into mature osteoclasts, ultimately resulting in a decrease in osteoclast formation and bone resorption. As BMMs treated with a high concentration of M-CSF exhibited significantly suppressed expression of adiponectin at both the mRNA and protein
A

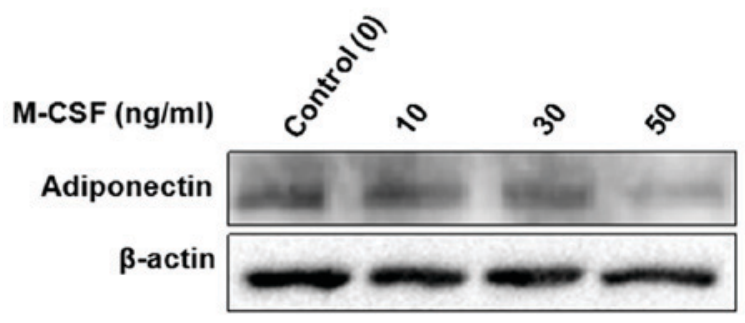

B

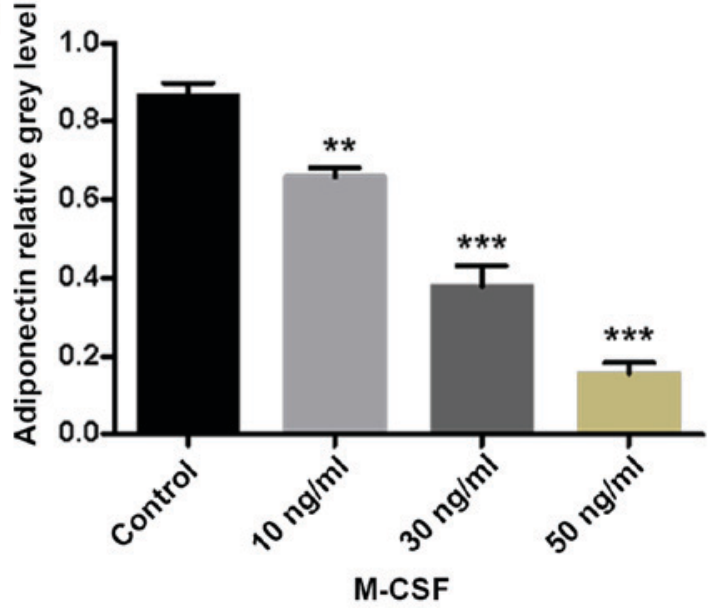

Figure 4. The expression of adiponectin in BMMs with M-CSF. (A) Adiponectin was inhibited in the presence of M-CSF, particularly, in the 50 ng/ml group. (B) The band intensity corresponding to adiponectin was quantified and normalized to $\beta$-actin and was presented graphically. ${ }^{* *} \mathrm{P}<0.01$, ${ }^{* * *} \mathrm{P}<0.001$ vs. control. BMM, bone marrow-derived monocytes; M-CSF, macrophage colony stimulating factor. 
levels, it is likely that BMMs can secrete a certain amount of adiponectin when cultured in M-CSF. It can be speculated that among the BMMs secreting endogenous adiponectin by autocrine, paracrine and endocrine mechanisms, the generated adiponectin will constantly reduce its own expression in BMMs stimulated with a high concentration of M-CSF via negative feedback regulation (36).

Nevertheless, there are several limitations of the present study that should be considered. First, it was not feasible to fully explore the molecular mechanism by which adiponectin exerts its effects on BMMs, including which signaling pathway is affected, which will be a focus of subsequent research. Second, these results are only based on in vitro experiments in BMMs; therefore, an in vivo experiment with an animal model will be required to verify the results and determine the potential clinical relevance of adiponectin in OP.

In summary, the present study is a clarification of direct effects of adiponectin on bone cells. Specifically, stimulation of osteoblast proliferation by adiponectin was demonstrated, together with inhibition of osteoclastogenesis. These findings have demonstrated and validated this via cell viability assay, osteoclastogenesis assay and detection of relevant proteins and genes by western blotting and RT-qPCR. Furthermore, primary cells were used as the research basis, which yielded more reliable results. This is due to commercial cell lines exhibiting biochemical alteration, which leads to variations in the cells. Accordingly, these findings support that adiponectin may be developed as a synthetic drug targeting the activity of osteoblasts or osteoclasts in the future, which may ultimately have utility for the treatment of OP.

\section{Acknowledgements}

Not applicable.

\section{Funding}

The present study was supported by the National Natural Science Foundation of China (grant no. 00019509) and the Gan-Po Talents Project 555 of Jiangxi Province.

\section{Availability of data and materials}

The datasets used and/or analyzed during the current study are available from the corresponding author on reasonable request.

\section{Authors' contributions}

XW conceived and designed the study, performed the experiments, analyzed the data, prepared reviewed and edited the manuscript. LH performed the experiments and analyzed the data. JL conceived and designed the study and revised the manuscript. All authors read and approved the manuscript.

\section{Ethics approval and consent to participate}

All animal experiments were conducted following the approval of the Institutional Review Board (Medical Ethics Committee) of the First Affiliated Hospital of Nanchang University (Nanchang, China).

\section{Patient consent for publication}

Not applicable.

\section{Competing interests}

The authors declare that they have no competing interests.

\section{References}

1. Vats A, Tolley NS, Polak JM and Buttery LD: Stem cells: Sources and applications. Clin Otolaryngol Allied Sci 27: 227-232, 2002.

2. Poudyal $\mathrm{H}$ and Brown L: Osteoporosis and its association with non-gonadal hormones involved in hypertension, adiposity and hyperglycaemia. Curr Drug Targets 14: 1694-1706, 2013.

3. Consensus development conference: Diagnosis, prophylaxis, and treatment of osteoporosis. Am J Med 94: 646-650, 1993.

4. NIH Consensus Development Panel on Osteoporosis Prevention, Diagnosis, and Therapy: Osteoporosis prevention, diagnosis, and therapy. JAMA 285: 785-795, 2001.

5. Harvey N, Dennison E and Cooper C: Osteoporosis: Impact on health and economics. Nat Rev Rheumatol 6: 99-105, 2010.

6. Kanis JA, Odén A, McCloskey EV, Johansson H, Wahl DA and Cooper C; IOF Working Group on Epidemiology and Quality of Life: A systematic review of hip fracture incidence and probability of fracture worldwide. Osteoporos Int 23: 2239-2256, 2012 .

7. Melton LJ III, Chrischilles EA, Cooper C, Lane AW and Riggs BL: Perspective. How many women have osteoporosis? J Bone Miner Res 7: 1005-1010, 1992.

8. South-Paul JE: Osteoporosis: Part I. Evaluation and assessment. Am Fam Physician 63: 897-904, 908, 2001.

9. Kanazawa I: Adiponectin in metabolic bone disease. Curr Med Chem 19: 5481-5492, 2012.

10. Kubota N, Terauchi Y, Yamauchi T, Kubota T, Moroi M, Matsui J, Eto K, Yamashita T, Kamon J, Satoh H, et al: Disruption of adiponectin causes insulin resistance and neointimal formation. J Biol Chem 277: 25863-25866, 2002.

11. Yamauchi T, Kamon J, Minokoshi Y, Ito Y, Waki H, Uchida S, Yamashita S, Noda M, Kita S, Ueki K, et al: Adiponectin stimulates glucose utilization and fatty-acid oxidation by activating AMP-activated protein kinase. Nat Med 8: 1288-1295, 2002.

12. Hotta K, Funahashi T, Arita Y, Takahashi M, Matsuda M, Okamoto Y, Iwahashi H, Kuriyama H, Ouchi N, Maeda K, et al: Plasma concentrations of a novel, adipose-specific protein, adiponectin, in type 2 diabetic patients. Arterioscler Thromb Vasc Biol 20: 1595-1599, 2000.

13. Luo XH, Guo LJ, Xie H, Yuan LQ, Wu XP, Zhou HD and Liao EY: Adiponectin stimulates RANKL and inhibits OPG expression in human osteoblasts through the MAPK signaling pathway. J Bone Miner Res 21: 1648-1656, 2006.

14. Jürimäe $\mathbf{J}$ and Jürimäe T: Plasma adiponectin concentration in healthy pre- and postmenopausal women: Relationship with body composition, bone mineral, and metabolic variables. Am J Physiol Endocrinol Metab 293: E42-E47, 2007.

15. Lewiecki EM: RANK ligand inhibition with denosumab for the management of osteoporosis. Expert Opin Biol Ther 6: 1041-1050, 2006.

16. Schett G, Hayer S, Zwerina J, Redlich K and Smolen JS: Mechanisms of Disease: The link between RANKL and arthritic bone disease. Nat Clin Pract Rheumatol 1: 47-54, 2005.

17. Szulc P and Delmas PD: Biochemical markers of bone turnover: Potential use in the investigation and management of postmenopausal osteoporosis. Osteoporos Int 19: 1683-1704, 2008.

18. Yamauchi T and Kadowaki T: Physiological and pathophysiological roles of adiponectin and adiponectin receptors in the integrated regulation of metabolic and cardiovascular diseases. Int J Obes 32 (Suppl 7): S13-S18, 2008.

19. Shinoda Y, Yamaguchi M, Ogata N, Akune T, Kubota N, Yamauchi T, Terauchi Y, Kadowaki T, Takeuchi Y, Fukumoto S, et al: Regulation of bone formation by adiponectin through autocrine/paracrine and endocrine pathways. J Cell Biochem 99: 196-208, 2006.

20. Belaaouaj A, Kim KS and Shapiro SD: Degradation of outer membrane protein A in Escherichia coli killing by neutrophil elastase. Science 289: 1185-1188, 2000. 
21. Adkison AM, Raptis SZ, Kelley DG and Pham CT: Dipeptidyl peptidase I activates neutrophil-derived serine proteases and regulates the development of acute experimental arthritis. J Clin Invest 109: 363-371, 2002.

22. Tkalcevic J, Novelli M, Phylactides M, Iredale JP, Segal AW and Roes J: Impaired immunity and enhanced resistance to endotoxin in the absence of neutrophil elastase and cathepsin G. Immunity 12: 201-210, 2000.

23. Ouchi N, Kihara S, Arita Y, Okamoto Y, Maeda K, Kuriyama H, Hotta K, Nishida M, Takahashi M, Muraguchi M, et al Adiponectin, an adipocyte-derived plasma protein, inhibits endothelial NF-kappaB signaling through a cAMP-dependent pathway. Circulation 102: 1296-1301, 2000.

24. Yamaguchi N, Argueta JG, Masuhiro Y, Kagishita M, Nonaka K, Saito T, Hanazawa S and Yamashita Y: Adiponectin inhibits Toll-like receptor family-induced signaling. FEBS Lett 579: 6821-6826, 2005.

25. Koga T, Inui M, Inoue K, Kim S, Suematsu A, Kobayashi E, Iwata T, Ohnishi H, Matozaki T, Kodama T, et al: Costimulatory signals mediated by the ITAM motif cooperate with RANKL for bone homeostasis. Nature 428: 758-763, 2004.

26. Burgess TL, Qian Y, Kaufman S, Ring BD, Van G, Capparelli C, Kelley M, Hsu H, Boyle WJ, Dunstan CR, et al: The ligand for osteoprotegerin (OPGL) directly activates mature osteoclasts. J Cell Biol 145: 527-538, 1999.

27. Livak KJ and Schmittgen TD: Analysis of relative gene expression data using real-time quantitative PCR and the 2(- $\Delta \Delta \mathrm{C}(\mathrm{T}))$ method. Methods 25: 402-408, 2001.

28. Wei X, Li G, Yang X, Ba K, Fu Y, Fu N, Cai X, Li G, Chen Q, Wang M, et al: Effects of bone morphogenetic protein-4 (BMP-4) on adipocyte differentiation from mouse adipose-derived stem cells. Cell Prolif 46: 416-424, 2013.
29. Chambers TJ: Regulation of the differentiation and function of osteoclasts. J Pathol 192: 4-13, 2000.

30. Glantschnig H, Fisher JE, Wesolowski G, Rodan GA and Reszka AA: M-CSF, TNFalpha and RANK ligand promote osteoclast survival by signaling through mTOR/S6 kinase. Cell Death Differ 10: 1165-1177, 2003.

31. Stanley ER, Berg KL, Einstein DB, Lee PS, Pixley FJ, Wang Y and Yeung YG: Biology and action of colony - stimulating factor-1. Mol Reprod Dev 46: 4-10, 1997.

32. Wang QP, Li XP, Wang M, Zhao LL, Li H, Xie H and Lu ZY: Adiponectin exerts its negative effect on bone metabolism via OPG/RANKL pathway: An in vivo study. Endocrine 47: 845-853, 2014

33. Boyle WJ, Simonet WS and Lacey DL: Osteoclast differentiation and activation. Nature 423: 337-342, 2003.

34. Yamaguchi N, Kukita T, Li YJ, Kamio N, Fukumoto S, Nonaka K, Ninomiya Y, Hanazawa S and Yamashita Y: Adiponectin inhibits induction of TNF-alpha/RANKL-stimulated NFATc1 via the AMPK signaling. FEBS Lett 582: 451-456, 2008.

35. Abu-Amer Y: NF- $\kappa B$ signaling and bone resorption. Osteoporos Int 24: 2377-2386, 2013

36. Dimitri P and Rosen C: The central nervous system and bone metabolism: An Evolving Story. Calcif Tissue Int 100: 476-485, 2017.

This work is licensed under a Creative Commons Attribution-NonCommercial-NoDerivatives 4.0 International (CC BY-NC-ND 4.0) License. 